\title{
Emergency Transcatheter Aortic Valve Implantation in A Patient with The Assistance of Intra-Aortic Balloon Pump
}

\author{
Yan $\mathrm{Xu}^{1}$, Pengkun Zhang ${ }^{1}$, Dengfeng Fang ${ }^{1^{*}}$ \\ ${ }^{1}$ Department of Anesthesiology, West China Hospital, Sichuan University \& The Research Units of West China (2018RUo12), \\ Chinese Academy of Medical Sciences, Sichuan, China
}

Corresponding Author: Dengfeng Fang, MD

Address: Department of Anesthesiology, West China Hospital, Sichuan university \& The Research Units of West China (2018RU012), Chinese Academy of Medical Sciences, No. 37 Guoxuexiang, Chengdu, Sichuan, 610041, China; Tel: +8628-8542-3593; Email:xdj9515@163.com

Received date: 14 July 2021; Accepted date: 08 August 2021; Published date: 14 August 2021

Citation: Xu Y, Zhang P, Fang D. Emergency Transcatheter Aortic Valve Implantation in A Patient with The Assistance of Intra-Aortic Balloon Pump. Asp Biomed Clin Case Rep. 2021 Aug 14;4(3):157-61.

Copyright (C) $2021 \mathrm{Xu} \mathrm{Y,} \mathrm{Zhang} \mathrm{P,} \mathrm{Fang} \mathrm{D.} \mathrm{This} \mathrm{is} \mathrm{an} \mathrm{open-access} \mathrm{article} \mathrm{distributed} \mathrm{under} \mathrm{the} \mathrm{Creative} \mathrm{Commons}$ Attribution License, which permits unrestricted use, distribution, and reproduction in any medium provided the original work is properly cited.

\begin{abstract}
Surgical aortic valve replacement (SAVR) is considered the gold-standard treatment for patients with severe aortic valve stenosis (AS), yet 30\% are considered inappropriate for SAVR on account of the advanced age and multiple comorbidities. Transcatheter aortic valve implantation (TAVI) provides an option for high-risk patients with severe AS, especially for those accompanied with acute cardiogenic shock and multiple organ dysfunction. Herein, we presented a case of a patient resuscitated successfully with TAVI in combination with intra-aortic balloon pump.
\end{abstract}

\section{Keywords}

Aortic Valve Stenosis, Cardiogenic Shock, Transcatheter Aortic Valve Implantation, Intra-Aortic Balloon Pump

\section{Introduction}

Aortic valve stenosis (AS) is the most common valvular disease in the Western world, especially among individuals above 60 years of age [1]. It is associated with a high rate of death if untreated. Surgical aortic valve replacement (SAVR) is considered the gold-standard treatment for patients suffering from severe AS. However, SAVR is not feasible in approximately $30 \%$ of the patients, due to advanced age and multiple comorbidities [2]. Complications such as cardiogenic shock and multiple organ dysfunction syndrome (MODS) pose a great challenge to SAVR, and lead to operative mortality as high as $21 \%$ [3]. Recently, interventional therapy such as transcatheter aortic valve implantation (TAVI) has provided an alternative option for these high- risk patients, [4-6] yet the feasibility for treating severe AS patients with cardiogenic shock and MODS has not been established. Herein, we presented an extremely severe AS case complicated with acute cardiogenic shock and MODS who successfully saved by emergency TAVI with the assistance of an intraaortic balloon pump (IABP). Written consent was received from the patient for the publication of this case report.

\section{Case presentation}

A 74-year-old male patient presented to the emergency department with progressive shortness of breath for several months. He also reported a harsh cough with occasional purulent sputum production. He had a history of AS, hypertension, and coronary artery 
Citation: Xu Y, Zhang P, Fang D. Emergency Transcatheter Aortic Valve Implantation in A Patient with The Assistance of Intra-Aortic Balloon Pump. Asp Biomed Clin Case Rep. 2021 Aug 14;4(3):157-61.

disease. His AS and coronary artery disease were treated with conservative treatment. Physical examination revealed a $5 / 6$ systolic murmur in the aortic area and bilateral lower extremity edema. The preoperative computed tomography (CT) threedimensional reconstruction and enhancement scan of the thoracic vessels revealed a calcified aortic valve and a slightly widened ascending aorta. Transthoracic echocardiography (TTE) and Transesophageal echocardiogram (TEE) demonstrated an extremely severe AS with the aortic valve area (AVA) of $0.5 \mathrm{~cm}^{2}$, peak AV velocity of $12.33 \mathrm{~m} / \mathrm{s}$, a significantly decreased left ventricular ejection fraction (LVEF) of $27.7 \%$, mild mitral regurgitation as well as tricuspid regurgitation (Fig-1).

His condition deteriorated rapidly with conservative management. Acute cardiogenic shock, renal failure, and respiratory failure developed after he was admitted to the cardiovascular surgical unit. His vital signs were as follows: heart rate (HR) $111 \mathrm{bpm}$, blood pressure (BP) 75/33 $\mathrm{mm} \mathrm{Hg}$, respiratory rate (RR) $24 \mathrm{bpm}$, and saturation of pulse oxygen $\left(\mathrm{SpO}_{2}\right)$ $70 \%-80 \%$ when given a reservoir bag mask of 6 $\mathrm{L} / \mathrm{min}$. Laboratory tests revealed $\mathrm{BNP}>35000$ $\mathrm{pg} / \mathrm{ml}$, urea $28 \mathrm{mmol} / \mathrm{l}$, serum creatinine $175.0 \mu \mathrm{mol} / \mathrm{l}$, AST $2373 \mathrm{IU} / \mathrm{L}, \quad$ ALT $1788 \mathrm{IU} / \mathrm{L}$, TB $131.7 \mu \mathrm{mol} / \mathrm{l}$, and DB 90.4 $\mu \mathrm{mol} / \mathrm{l}$. Arterial blood gas test showed $\mathrm{pH}$ 7.288, $\mathrm{PCO}_{2} 53 \mathrm{~mm} \mathrm{Hg}, \mathrm{PO}_{2} 67 \mathrm{~mm} \mathrm{Hg}$, and $\mathrm{BE}-6.96 \mathrm{mmol} / \mathrm{l}$. The patient was transferred to the cardiac intensive care unit (CCU) after tracheal intubation. As his conditions deteriorated, IABP was placed to improve coronary perfusion pressure in CCU.

The patient was then scheduled for TAVI with the assistance of IABP and a high dose of epinephrine and norepinephrine. In the hybrid operating room (OR), his baseline $\mathrm{HR}$ was $109 \mathrm{bpm}, \mathrm{BP}$ was $80 / 40 \mathrm{~mm} \mathrm{Hg}$, and $\mathrm{SpO}_{2}\left(\mathrm{FiO}_{2} 50 \%\right)$ was 92\%. General anesthesia was induced with $2 \mathrm{mg}$ midazolam, $20 \mu \mathrm{g}$ sufentanil, and $50 \mathrm{mg}$ rocuronium, and then maintained with $1-1.5 \%$ sevoflurane. A bolus of $1 \mathrm{mg} / \mathrm{kg}$ dose of heparin was administrated. Then the surgical incision was made in the fifth intercostal space to expose the cardiac apex. Thereafter, a guidewire was inserted from the apex, passing through the aortic valve, and finally was placed in the descending aorta. Then the balloon and the delivery catheter were inserted into the ascending aorta with the guidance of the guidewire. After the implantation of a 25-mm SAPIEN transcatheter heart valve, angiography and TEE were performed to verify the position (Fig-2).

Eventually, the heart valve was released and deployed with self-expansion. Immediately after deployment of the valve, the patient demonstrated significant hemodynamic improvement and the peak AV velocity dropped from $12.33 \mathrm{~m} / \mathrm{s}$ to $3.2 \mathrm{~m} / \mathrm{s}$, with epinephrine reduced from 0.3 to $0.1 \mu \mathrm{g} / \mathrm{kg} / \mathrm{min}$ and norepinephrine was reduced from 0.8 to 0.3 $\mu \mathrm{g} / \mathrm{kg} / \mathrm{min}$ iv. The surgery lasted 120 minutes, and the whole procedure was smooth and uneventful. IABP was used intraoperatively to assist circulation. No adverse cardiac events, e.g., cardiac arrest or malignant arrhythmia, occurred in the OR.

The patient was then transferred to $\mathrm{CCU}$ and carefully weaned off catecholamines. He was extubated two days later when BNP decreasing to $4667 \mathrm{pg} / \mathrm{m}$. The IABP was removed on the fourth postoperative

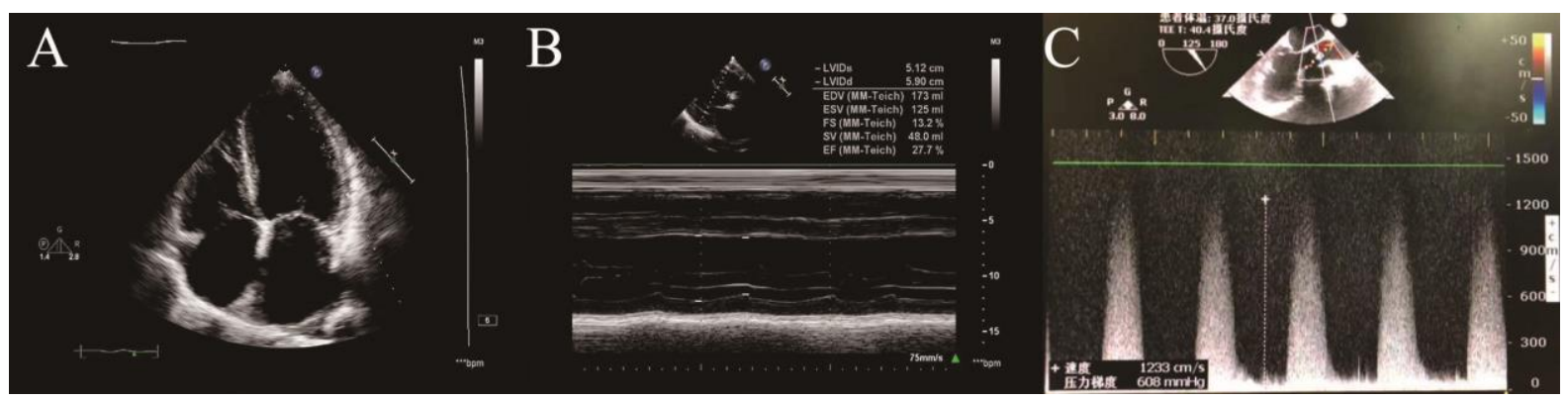

Fig-1:

TTE and TEE findings before operation. (A-B) The preoperative TTE findings before operation; (C) The preoperative TEE findings before operation. 
Citation: Xu Y, Zhang P, Fang D. Emergency Transcatheter Aortic Valve Implantation in A Patient with The Assistance of Intra-Aortic Balloon Pump. Asp Biomed Clin Case Rep. 2021 Aug 14;4(3):157-61.

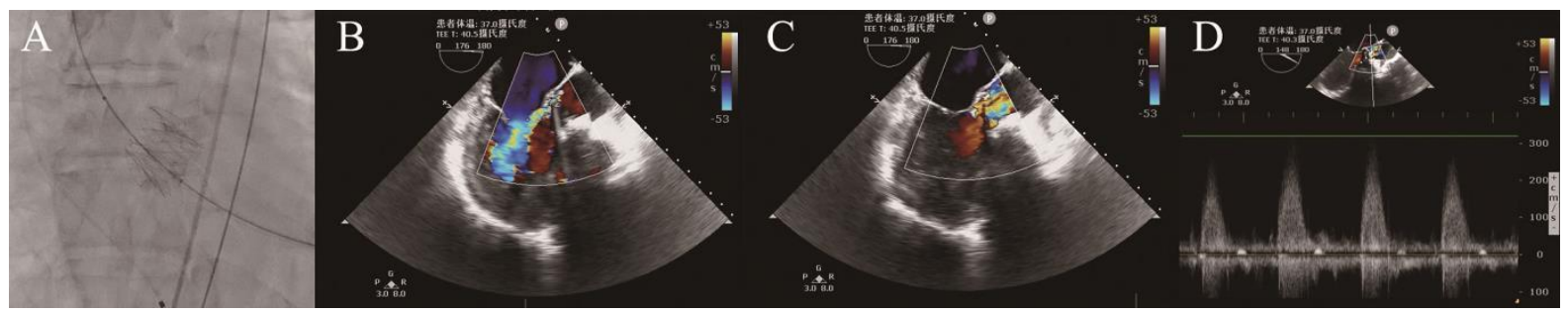

Fig-2:

The fluoroscopic and TEE images after deployment of the prosthetic valve. (A) The fluoroscopic image after deployment of the prosthetic valve; (B-D) TEE images after deployment of the prosthetic valve.

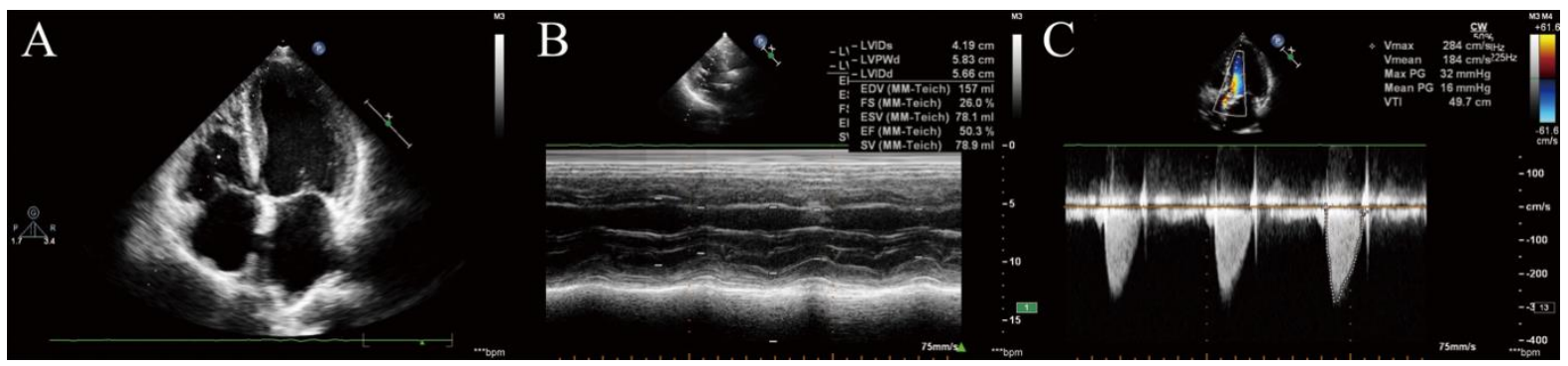

Fig-3:

Two-dimensional echocardiography findings in the postoperative period (A-C).

day. Simultaneously, the renal and respiratory function was gradually improved. The patient was discharged from hospital 11 days after surgery without any complications. In the six-month followup, the patient's cardiac function was improving from NYHA class IV to II. Additionally, the TTE showed the mean transvalvular gradient and AVA were $16 \mathrm{~mm} \mathrm{Hg}$ and $1.4 \mathrm{~cm}^{2}$ respectively, and LVEF increased to $48 \%$ without any inotropic agents support (Fig-3).

\section{Discussion}

Severe AS with acute cardiogenic shock and MODS are lethal and require prompt treatment $[7,8]$. SAVR remains the first choice in younger or lower risk AS patients, yet critically ill elderly patients are at highrisk for SAVR [9]. Therefore, TAVI has been increasingly recommended for the avoidance of cardiopulmonary bypass, traditional sternotomy and cardioplegia [9]. Nevertheless, the feasibility of TAVI for treating severe AS patients with acute cardiogenic shock and MODS has not been established. In this article, we presented an extremely severe AS case with above complications, successfully resuscitated emergency TAVI under the assistant of IABP.

In our case, the patient was admitted with cardiogenic shock and MODS. Following short-term conservative medical management, his condition continued to deteriorate. Then, IABP was employed to enhanced myocardial perfusion and support circulation as a bridging therapy to TAVI. IABP is inflated during diastole to enhanced myocardial perfusion, and deflated during systole to reduce cardiac afterload. Moreover, IABP placement also permitted reduction in vasopressor requirements [10]. Although using IABP in combination with VA-ECMO is a reasonable strategy for cardiogenic shock, the effectiveness of this combination remains controversial in patients with limited survival and is occasionally criticized for its high cost. Thus, ECMO was not applied due to its specific complications (cardiac thrombosis and the coronary or cerebral hypoxia) and high cost in this case. Notably, the anesthetist played a critical role during the whole procedure. The anesthetist must be prepared to treat any sudden arrhythmias such as ventricular fibrillation or atrioventricular block, as a result of rapid ventricular pacing or manipulation of catheters within the heart. In this case, general anesthesia was used because it allows control of the procedure with a secure airway in completely immobile patient [11]. More importantly, general anesthesia allows the use of transesophageal echocardiography, which can provide important information perioperatively. In addition, a "titrate to effect" induction method is necessary, and the 
anesthetics that do not rely on renal and liver function are better choice. Hypotension should be treated aggressively with vasoactive agents, followed by management of the underlying cause. The main goal of intraoperative management is to protect the failing heart and organ by optimizing oxygen supply and decreasing oxygen demand, and excessive fluid infusion should be avoided except for unexpected massive bleeding. With the meticulous anesthetic management and IABP support, the whole TAVI procedure was smooth and uneventful.

In summary, TAVI is a realistic life-saving option for these patients with severe AS and cardiogenic shock who would otherwise encounter death. The development of TAVI has allowed successful treatment for patients who were previously deemed too risky for SAVR, and bridging therapies such as IABP and vasopressors are important supplement treatments. However, effects of TAVI remain to be established in such high-risk patients on long-term outcome.

\section{Funding}

This work was supported by the 1.3 .5 project for disciplines of excellence, West China Hospital, Sichuan University (2018HXFHo46).

\section{Conflict of Interest}

The authors have read and approved the final version of the manuscript. The authors have no conflicts of interest to declare.

\section{Acknowledgements}

None

\section{References}

[1] Iung B, Baron G, Butchart EG, Delahaye F, GohlkeBärwolf C, Levang OW, Tornos P, Vanoverschelde JL, Vermeer F, Boersma E, Ravaud P, Vahanian A. A prospective survey of patients with valvular heart disease in Europe: The Euro Heart Survey on Valvular Heart Disease. Eur Heart J. 2003 Jul;24(13):1231-43. [PMID: 12831818]

[2] Nkomo VT, Gardin JM, Skelton TN, Gottdiener JS, Scott CG, Enriquez-Sarano M. Burden of valvular heart diseases: a population-based study. Lancet. 2006 Sep 16;368(9540):1005-11. [PMID: 16980116]

[3] Carabello BA, Green LH, Grossman W, Cohn LH, Koster JK, Collins JJ Jr. Hemodynamic determinants of prognosis of aortic valve replacement in critical aortic stenosis and advanced congestive heart failure. Circulation. 1980 Jul;62(1):42-48. [PMID: $7379284]$

[4] Smith CR, Leon MB, Mack MJ, Miller DC, Moses JW, Svensson LG, Tuzcu EM, Webb JG, Fontana GP, Makkar RR, Williams M, Dewey T, Kapadia S, Babaliaros V, Thourani VH, Corso P, Pichard AD, Bavaria JE, Herrmann HC, Akin JJ, Anderson WN, Wang D, Pocock SJ; PARTNER Trial Investigators. Transcatheter versus surgical aortic-valve replacement in high-risk patients. $\mathrm{N}$ Engl J Med. 2011 Jun 9;364(23):2187-98. [PMID: 21639811]

[5] Haude M. Management von Herzklappenerkrankungen: ESC/EACTS-Leitlinie 2017 [Management of valvular heart disease: ESC/EACTS guidelines 2017]. Herz. 2017 Dec;42(8):715-20. German. [PMID: 29188357]

[6] Liu Z, Kidney E, Bem D, Bramley G, Bayliss S, de Belder MA, Cummins C, Duarte R. Transcatheter aortic valve implantation for aortic stenosis in high surgical risk patients: A systematic review and meta-analysis. PLoS One. 2018 May 10;13(5):eo196877. [PMID: 29746546]

[7] Rosenhek R, Binder T, Porenta G, Lang I, Christ G, Schemper M, Maurer G, Baumgartner H. Predictors of outcome in severe, asymptomatic aortic stenosis. N Engl J Med. 2000 Aug 31;343(9):611-17. [PMID: 10965007]

[8] Carabello BA, Paulus WJ. Aortic stenosis. Lancet. 2009 Mar 14;373(9667):956-66. [PMID: 19232707]

[9] Schmidt T, Frerker C. Treatment Challenges in Patients with Acute Heart Failure and Severe Aortic Valve Stenosis. Curr Cardiol Rep. 2019 Apr 22;21(6):47. [PMID: 31011842]

[10] Al-Mufti F, Morris N, Lahiri S, Roth W, Witsch J, Machado I, Agarwal S, Park S, Meyers PM, Connolly ES, Claassen J. Use of Intra-aortic- Balloon Pump Counterpulsation in Patients with Symptomatic Vasospasm Following Subarachnoid Hemorrhage and Neurogenic Stress Cardiomyopathy. J Vasc 
Citation: Xu Y, Zhang P, Fang D. Emergency Transcatheter Aortic Valve Implantation in A Patient with The Assistance of Intra-Aortic Balloon Pump. Asp Biomed Clin Case Rep. 2021 Aug 14;4(3):157-61.

Case Report

Interv Neurol. 2016 Jun;9(1):28-34. [PMID:

27403221]

[11] Welt FG, Davidson MJ, Leon MB, Eisenhauer AC.

Transcatheter aortic valve replacement. Circulation.

2011 Dec 20;124(25):2944-48. [PMID: 22184044]

Keywords: Aortic Valve Stenosis, Cardiogenic Shock, Transcatheter Aortic Valve Implantation, Intra-Aortic Balloon Pump 